\title{
A Suggested Conception For Developing The Intellectual Capital In Egyptian Weight Lifting Federation In The Light Of Knowledge Economy
}

\author{
Dr.Mostafa Antar Zidan Farag \\ Department of Sports Management and Recreation, \\ Faculty of Physical Education, Assiut University
}

\section{Introduction and the study problem:}

The world continuously witnesses successive and quick developments that affected business environment and organizations position, where it requires to keep pace with its performance with what these changes impose of requirements, where the existence in the market is no longer for the best organizations only, but for organizations that achieve excellence and that are characterized with the competitive capacity.

In our present time, the ratio of finding knowledge and spreading it became increase remarkably, due to the speedy progress in information and communication technology in which it's prices reduced noticeably, particularly the costs of computerization and electronic networks. Economical changes were produced that led to the appearance of different economical forces, all of them try to move the global economy towards its goals and interests and led also to what is known with the phenomenon of globalization. Knowledge is considered the engine for productivity and economic development. It also leads to concentration on the role of information and technology.

This increase speed in spreading knowledge led to the speed spreading for modern technology and production competence led to the increase of competition severity on global level. Knowledge became a good that is sell and purchased and if it is functioned rightly, it influenced in one way or another by using intense information and advanced technology that creates an additive value and a larger development leading finally to the transfer towards the cognitive economy. This transfer needs a set of components including concerning with developing education and knowledge , developing the creative abilities, providing the infrastructure for information and communication technology and providing an appropriate economical environment in which the international bank called the pillars of knowledge economy . To evaluate knowledge and it's economy, a number of international organizations cooperate with some statistical institutions and departments to achieve conclusions serving orientation towards measuring the indicators precisely ( Kestutis \& Rasa , $2006: 40$ ) ( Albawab, 2001:2)

Earth, labor and capital are the three basic factors for production in ancient economy, technical knowledge, creativity, intelligence and information became the important assets in the new economy. The intelligence that is embodied in computer and technology programs through wide range is one of the important production exceeding the importance of the capital or the materials or the labors. United nations estimates that knowledge economics capture $7 \%$ of gross national - global product and develop with a ratio of $10 \%$ annually. It is worthy noted that $50 \%$ of the productivity development in European union for example is a direct result for using and producing information and communication technology (4), and now several terms are related with this develop such as intelligent technology, virus marketing, disruptive innovations and others.( Ela ,2011:2). 
From this point of view, modern management is characterized with basic features representing in directing the management efforts and activities on achieving clients satisfaction and exploiting creative energies and human forces, because humans are the basic pillar of success, so it believes team work to help employees on creativity, innovation and serious sharing in achieving a larger level of excellence and superiority through specific systems and developed tightly, decisions are taken based upon collecting and using data depended upon observation, experience and experiment to make use of the facts in the process of changing and cause it . (Elserafy, 2003: 34 )

The findings of Mayson A, H, study ( 2016 )(21) indicates that institutional performance excellence is related with following modern management methods in the institutional work "Mohammed Guam " ( 2009 ) defines knowledge as using and functioning technicality in purpose of improving life style with all its aspects and activities through benefiting from information, the internet and different information applications .( p. 7 ).

In view of the scientific and technological changes and developments particularly pertaining information and communication technology and the economical trends based upon knowledge, the management thinking has new attitudes and developments keeping pace with these scientific and technological changes and developments that appear in a form of intellectual and scientific contemporary management concepts including " total quality management, knowledge management , electronic management, crisis management, risks management, competencies management, strategic management, change management, time management, intellectual capital management, restructure. From previously mentioned of modern concepts, a total concept was produced including all these concepts through the features in which the management is characterized that is excellence. (Magdy, 2004: 31 )

Intellectual capital, under the competitive economy and information age, became the real capital for organizations as the corner that play the basic role in the process of creativity and innovation, it is the leader in the process of change and innovation, consequently is able to transfer knowledge to value, hence to a competitive privilege, meaning that the gravity center in generating the value is transferred from exploiting the natural ( physical ) resources to exploit intellectual (intangible ) origins and from the law of returns reduction ( that is applied on the physical goods ) to the law of increasing the returns ( in terms of knowledge and thoughts )(Mahmoud, Ajlouni, 2010: 44 )

The concept of intellectual capital and what is opposed of physical and intangible origins of the most recent concepts that appeared in the field of management in general and is considered the basic engine of growth in contemporary business organizations and the basic factor in achieving the competitive privilege .(Hany,2008:17)

The contemporary organizations seek under very competitive environment to gain a competitive privilege than other organizations working in the same activity through adding the client value and achieving excellence by exploiting the intellectual and mental energy of the individuals, where the exploitation of these energies is an important role in making the non material assets ( the intellectual capital ) a competitive advantage through supporting human potentials and energies and helping them in discovering their skills ( Reda, 2009:2) 
This accords with what the studies that were conducted on the intellectual capital, economy and knowledge indicated, for example the study of " Ali Thajill, Salima Tebaibia ( 2011 ) (12), " Taha Hussein " ( 2010 )(8), " Maher Almahruk " ( 2009 )(14), that the use of the human abilities and the multiple creative abilities of the employees in the organizations leads to the increase of the management and technical abilities for these organizations with the work increase and it's competitive privilege.

As the intellectual capital doesn't drain away but it increases through increasing employees skills, information and knowledge in the organization, that is it's productive age increases with the increase of the creative abilities that works on increasing technological and functional perfection, hence increasing the productivity leading to lower the cost of the productive unit or the offered service, hence achieve the competitive privilege .( Saleh , 2011:378)

Hence, the contemporary institutions became based upon the science and knowledge or the information and this imposed following the performance management and with different ways on it than what was prevalent in the past by adopting a set of development and improvement accesses. Investment in the knowledge aspects or the intangible components is considered of a big importance for what it achieves of cost savings and increase the competence and productivity, particularly with encouraging the spirit of creativity and innovation in the process of developing the human resources, hence, came the increase interest in the human resources through the investment in the intellectual capital. (Ali , Salima , 2011:2 )

Indicates that the organization ability on transferring the intellectual capital to a value depends upon the value type in which the organization desires to achieve from it's investment in the intellectual capital that can take several forms:

a) Achieving profits.

b) Achieving the competitive advantage through increasing the creative and innovative abilities.

c) Improving the relations between the clients and suppliers.

d) Improving the productivity and reducing the cost.

e) Improving the employee's attitudes and the outer mental image.

f) Increasing the market share and establishing a strong competitive center.

(Ahmed ,2004: :35)

For the sake of this, the real competition between different organizations became in the attempt to establish the intellectual capital with all possible methods , even with polarizing the excellent components of the competitors or other organizations . Employees in sport organizations of knowledge and experience are considered the basic source of the intellectual capital and the interest multiplies with developing systems and technicalities of managing the intellectual capital to treat positively with these rarely intellectual resources of value. (Alsalmy, $2008: 45$ ).

Sport aspect is considered one of the most important real investment aspects of the human wealth where it includes several of the educational processes of divergent directions and aspects aiming at educating the generations to enrich all life aspects. Sport activity is characterized than the rest of other activities that it is the aspect of practice and interaction about modifying the behavior of the human being. ( Talha, Adela , 1997: 25 ) . 


\section{So we find that knowledge rests in it's base on four pillars as following:}

1- Creativity ( study and development ) : an effective system of commercial connections with the academic institutions and other organizations that can cope with the continuous knowledge revolution, absorb and adapt with the local needs .

2- Education : it is of the basic needs for the productivity and economical competition, where the governments should provide skillful or creative manpower or the human capital that is able to integrate modern technologies in work and increase the need to information and communication technology, as well as the creative skills in the educational curricula and learning programs lifelong .

3-The infrastructure based upon information and communication technology: that facilitates spreading and preparation of information and knowledge and adapt it with the local needs to support the economical activity and activate the projects on producing high additive values.

4- The wise governance: based upon strong economical bases that can provide all law and political frames that aim at increasing the productivity and development. These include policies that aim at making information and technology more available and easiness, reducing customs tariff on technology productions and increasing the competitive ability for small and medium institutions .(Maher, 2016:9)

Yahia adds , quoted from " Ashraf Sobhy " ( 2010 ) that sport institutions are like any institution inside society in terms of structuring and building. Sport institution is not different from other ones, it can be studied and classified on more than one level and with more methods according to activities nature and works size in which the institution makes .( Yahia,2010:147)

From the above, the researcher sees that successful sport institutions are the ones able to develop it's competitive abilities and adapt with continuous change in the present time and needs of labor market. Developing the intellectual capital in sport institutions in general and Egyptian weight lifting federation in particular became an urgent need for present and future. This necessity was imposed by the accelerator changes and globalization, so orienting towards quality and excellence became inevitable so that the gap with the advanced world can be bridged, seek with fixed and quick steps towards advancement and pioneering, excellence is no longer a choice, but it became an inevitable necessity imposed by global transformations . Because sport federations are charged with preparing an influential class in sport society and with it's natural role in coordinating it's sport activities, the burden is on the federation in confronting the challenges under knowledge magnification, the advancement of science and technology and modern variants imposed the necessity of directing towards achieving excellence in sport institutions .

The Egyptian Weightlifting Federation exercises its powers in light of the state's general policy. These specializations and responsibilities throw on the federation shoulders the responsibility of following modern management methods , hence applying them to keep pace with the current global developments, as well as to confront all the problems in which weight lifting sport faces and threatens it's structure. Through the interview that the researcher conducted and analyzing the 
studies related with Egyptian weight lifting federation, it is shown that the employees in the field of weight lifting sport have several deficiencies in cognitions and abilities of work that lead to causing several problems and management obstacles that hinder them from performing the required works with the best amount of competence and effectiveness and the last ones are the problems of camps, board of directors , general assembly and there is no sufficient communication with the branches subjected to the federation in different governorates. All these are due to the top departments uninterested in developing the intellectual capital for the employees, not providing the necessary financial support through dedicating a budget to spend on the training activities and the employees development, the littleness of the physical requirements that are necessary to enhance benefiting from using information technology inside it and not taking decisions to reward the individuals that are characterized with creative and innovative work .

Knowledge economy requires also in sport field the necessity of providing special skills in leaders and managers to find an appropriate organized structures in a world in which the intellectual capital and knowledge are two keys for the economic progress. These structures must contribute in facilitating cooperation, enhancing the process of learning and encouraging exchanging knowledge between the employees . This what the study of both " Maher Mohsen " ( 2016$)^{(15)}$, Myson Ali ( 2016$)^{(21)}$, Lawayza Farhaty ( 2016$)^{(13)}$ confirmed that that there is a strong relationship between managing the intellectual capital and the institutional performance .Prescriptions of achieving the organizational success in knowledge economy contradict with the method of authoritative and hierarchical leadership that loses it's executions and is resisted. When the management aims at forming an innovative team work and able to perform work with competency and autonomy, the dependence on the method of " sharing and cooperation ", making a system to encourage the employees on the competence performance became closer to achieve better results on the organization, consequently the organization goals are achieved to the fullest possible extent. This what the results of both " Ahmed Abduallah "( 2016) ${ }^{(3)}$, Mohadese \& Mohammed "(2016 $)^{(28)}$ indicated that there is a positive relationship between the intellectual capital and the components of the human capital , structural capital and clients with the organization creativity .

So, moving towards the future, requires developing the human performance and achieving good cognitive excellence achieving the positive results. This agreed with the results of Karimi \& Sheikhali (2014) ${ }^{(30)}$, Mitchell (2010) ${ }^{(27)}$, and proceeding from Egyptian weight lifting federation seek to achieve peak performance level whether on the individuals level or the system as a whole, the researcher found that it was of the big importance in improving the ability on measuring and managing the intellectual capital in Egyptian weight lifting federation that is reflected on the good knowledge inside Egyptian weight lifting federation, consequently it's institutional performance .

In this context, the researcher feels the importance and advantages that can be gained from studying this problem at Egyptian weight lifting federation. Through this frame, this study seeks to develop " a suggested conception for developing the intellectual capital at Egyptian weight lifting federation in the light of knowledge economy " 
Interested in the intellectual capital is one of the most prominent challenges in which human resources management faces because of the urgent need to organize both of creativity, innovation and the cognitive work methodologically where the intellectual capital focuses on the creative and innovative energies for the employees in the organization and how to discover, invest and maintain it considering that the contemporary organizations look to it's human resources as the most expensive ones and the more valuable origins . (Adel , 2007:2).

\section{Aim of the study:}

The current study aims to build a proposed vision for developing the intellectual capital of the Egyptian Weightlifting Federation in the light of the knowledge economy.

\section{Questions of the study:}

- What is the reality of managing the intellectual capital of the Egyptian Weightlifting Federation in light of the knowledge economy?

\section{Keywords:}

\section{1- The intellectual capital:}

The intellectual capital is a set of skills available in the organization that is characterized with broad knowledge to be able to make the organization globally through responding to clients requirements and the opportunities in which the technology provides . "Mitchell (2010.3)".

\section{2- The competitive privilege:}

That originates once the institution discovers new methods more effective than these used by the competitors ( Seliem , $2007: 790$ )

\section{3- Knowledge economy:}

It is a new stage that human organizations experiences by which it transforms from the traditional economy to a new economy based upon the knowledge, where the transformation is from dependence on the raw material, capital equipment to concentrate on information, knowledge and centers of education and studying . (Kestutis \&Rasa, $2006: 10$ ) .

\section{The study Procedures:}

\section{Study Approach:}

The researcher used the descriptive method (survey studies) for it's appropriateness for the study nature.

\section{Community and sample of the study:}

Community of the study represents members of technical and management committees in the federation, as well as employees in the federation and director of financial and management federation and branches managers. The sample of the study was selected with class random method of (132) individuals, and the following table (1) shows this : 
Table ( 1 )

Classifying the study sample

\begin{tabular}{c|c|c}
\hline \hline Serial & The class & Number \\
\hline \hline 1 & $\begin{array}{c}\text { Members of technical management committees } \\
\text { and employees in the federation and branches }\end{array}$ & 110 \\
\hline 2 & Federation managers & 2 \\
\hline 3 & Mangers of the branches ( financial - executive ) & $\mathbf{2 0}$ \\
\hline \hline
\end{tabular}

Tools of data collection :

To collect the study data, the researcher used the following :

\section{A questionnaire of managing the intellectual capital at Egyptian weight lifting federation:}

\section{A-Determining axes of the questionnaire:}

Through taking cognizance previous studies related with the study variables and the scientific references, it was found a set of axes. They were (5) axes. The form was presented on the experts of (10). "Annex (1) to recognize :

-The extent of the primary axes appropriateness and sufficiency .

- Modifying or deleting or adding any axis of the primary ones .

Table (2) shows the percentage of the experts opinion survey about the questionnaire axes .

Table (2)

The percentage of the experts opinion survey about the questionnaire axes $(n=10)$

\begin{tabular}{c|c|c|c|c}
\hline \hline Serial & The suggested axes & Appropriate & Inappropriate & The percentage \\
\hline \hline 1 & The human capital & 10 & - & $100 \%$ \\
\hline 2 & The intellectual origins & 7 & 3 & $70 \% * *$ \\
\hline 3 & The structural capital & 10 & - & $100 \%$ \\
\hline 4 & Renewal capital & 8 & 2 & $80 \% * *$ \\
\hline 5 & Relations capital & 10 & - & $100 \%$ \\
\hline \hline
\end{tabular}

It is shown from table (2) that the percentage for the experts agreement on the axes ranged between $(70 \%, 100 \%)$, so the axes were accepted and all these axes were integrated in three primary axes that are the human capital ( meaning the employees and what they possess of accumulated cognitions and experiences ), the structural capital ( representing in knowledge and different intellectual properties that still remain in the organization after the members leave it and is stored in data bases and organized documents and structures ), relations capital ( representing in the value obtained from the organization dealings with the external environment from clients, suppliers , competitors and others ). The hubs that were merged are intellectual origins with human capital, and renewal capital with relationship capital.

\section{$B$-Formulating the questionnaire statements :}

In the light of the previous table (2) results, the researcher developed a number of statements under each axis in the light of the relative importance of the axes where it included in the sum (39) statements in its initial form ( annex 3), distributed as 
follows : the human capital (15) statements, the structural capital (12) statements, relations capital (12) statements. When formulating the statements, it was considered to be simple and understanding to be presented on the experts ( annex 1) to show the opinion on :

- The extent of the suggested statements appropriateness or modifying or deleting or adding other statements .

The following table (3) illustrates the percentage of the experts opinions agreement about the questionnaire statements :

Table (3) displays that the percent of the experts opinions about the questionnaire axes statements ranged between $(70 \%: 100 \%)$. The researcher accepted the statements that have the percent of $70 \%$ or more of the experts agreement. So, the researcher found to design the questionnaire form in its final form (annex 4 ) and included (39) Phrase.

\section{5- Exploratory study :}

The researcher applied the questionnaire on a sample of ( 20 ) individuals from the study community and outside the basic study through the period from 13/1/2019 to 29/1/2019 in purpose of :

1-Confirming the extent of the statements appropriateness and clearness of the sample in which the questionnaire was applied .

2- Determining the time of the questionnaire application and finding the scientific coefficients of the form ( validity, reliability ).

The results of the pilot study displayed that the questionnaire was appropriate in terms of the formulation and the used language and there were no comments that suggest ambiguity or not understanding.

The scientific coefficients of the questionnaire :

Firs : validity :

\section{A- The validity of the internal consistency between the statements and sum of each axis of the questionnaire :}

To find the form validity, the researcher depended on ascertaining the internal consistency validity of the form statements . Correlation coefficient was calculated between the score of each statements of the questionnaire and the total sum of the axis in which they belong, as well as between the axes and the total sum of the form and table (4) shows this .

It is shown from the previous table that the correlation coefficients between the form axes and it's total sum ranged between ( $0.58: 0.86$ )and they are significance at the level 0.5 since it is bigger than the tabulated $(r)$ value .

\section{Second: reliability:}

To find the form reliability, the researcher used half split method for the form statements .Correlation coefficient was calculated between the single and couple statements for each axis of the questionnaire and between the single and couple statements of the questionnaire as a whole and table ( 5 ) shows this . where the calculated ( $\mathrm{r}$ ) value ranged between ( $0.688: 0.879$ ) and it is bigger than the tabulated ( $r$ ) value at a significance level ( 0.05 ) giving a direct significance of the questionnaire axes reliability as a whole. 


\section{6- Applying the questionnaire in it's final form :}

After conducting the scientific coefficients of the questionnaire and ascertaining the statements validity and reliability and settled in it's final form including (39) statements, the questionnaire was applied in it's final form on the individuals of the study sample from $1 / 2 / 2019$ to $2 / 3 / 2019$ according to triple estimation balance ( agree - somewhat agree - disagree ). The questionnaire statements were corrected, where the response (agree) was given (3) scores, and somewhat agree (2) scores and disagree (1) score . Data were collected, organized, tabulated and treating statistically .

The researcher used the statistical program ( SPSS-v25) to treat data statistically and the researcher used the following statistical methods in the present study :

(Arithmetic mean -standard deviation - correlation coefficient - the estimated score the percentage )

\section{Results and discussion and their interpretation:}

To achieve the study goals and responding it's questions and in the limits of what the researcher found of data through the statistical analysis, the following questions were answered :

The researcher used the relative weight and the achievement score to interpret the results. The achievement score were (3) scores as follows:

$3=$ ascertained $2=$ ascertained somewhat $\quad 1=$ not ascertained

* lower confidence limit $=0.59 \quad$ *upper confidence limit $=0.75$

\section{Answer to the first question, which states:}

- What is the reality of managing the intellectual capital of the Egyptian Weightlifting Federation in light of the knowledge economy?

It is shown from table ( 6 ) that mean responses of the sample individuals about the statements of the first axis " the human capital " ranged between ( $0.39: 0.66)$, where the mean response of the axis as a whole was ( 0.51$)$.

Responses of the study sample individuals were on behalf of the response that is more frequent that is "No" , except the statements $(3,4,7,13)$ on behalf of the response " somewhat " and the responses don't indicate to "Yes ".

The researcher attributes this finding to the very negligence by the administrative responsible leaderships inside Egyptian weight lifting federation for the concept and the importance of the human capital as the basic and effective resource in achieving high competence and value for the federation and the primary role in which it plays in the process of creativity and innovation . It is the resource that capable of transferring the unique knowledge to an economic value and in the case of not determining the result effect of this negligence that makes the federation performance and it's accomplishments a weak position before the public opinion .

The findings of ( Taha H. , 2010 ) (8) study indicates to the importance of achieving good training by the specialized administrative authorities in which the organization is subject to, since this contributes in constructing and achieving goals and vision of good administrative work . 
The researcher attributes this finding also that Egyptian weight lifting federation has a set of routine administrative rules and regulations that govern employees behaviors, consequently there is no development in these regulations but from the department of youth and sport and Egyptian weight lifting has no the infrastructure that is appropriate to apply the total electronic system for all from employees and beneficiaries .

These findings accord with the findings of (Adel Hahoush 2007)(9) study indicating that the management work inside the institution related with the administrative rules and procedures in the work and the institutions must coordinate with different authorities in constructing different training programs for the employees .

The percents of the statements ( 7, 4 ) range between lower and upper of confidence limit indicating to it's ascertainment moderately in the reality of managing the human capital in Egyptian weight lifting federation and that the federation encourages creativity and innovation with the major interest with the suggested thoughts and solutions in work .

It is shown from the previous findings that there are some problems in Egyptian weight lifting federation in the process of selecting, appointing and contracting with the human components of the positive effect in the work. There is no a sufficient information system to develop the basic standards to serve the clients or the employees appropriately. The findings displayed the littleness of a sufficient budget for Egyptian weight lifting federation in preparing the special training courses and deepening on the training courses offered from the department only and there is no an electronic system inside the federation working on providing the sufficient information of different activities in the federation .

These findings differ from the findings of both (Ahmed E , 2016 )(3) , ( Reda I, 2009 )(4) study indicating the necessity of constructing the training programs that are necessary for the employees inside the organizations and working on achieving the best institutional performance for developing the human component to achieve the best findings of the positive effect to achieve work goals .

The statements $(13,12,6)$ respectively came with a little percent of the lower confidence limit indicating to it's ascertainment in an average percent, not strong in the human capital inside Egyptian weight lifting federation that indicates that the federation is keen to provide information and data but not in a continuous and sequence way and there is no overall vision to compare the federation works with other similar federations .

The researcher attributes also this finding that the high management in Egyptian weight lifting is not interested in the process of continuous training for the employees leading to not developing the cognitive and practical skills and they haven't the necessary and continuous update information and data of the services and activities inside Egyptian weight lifting federation .

The findings of both ( Myson A , 2016 ) (21), (Lawayza F, 2016)(13) study indicate the necessity of interested in providing good human element because it is the basis of the institutional work to organizations success, where the institutions success resides in what they possess of human capacities that are trained in a good way . 
Most remaining statements came less than the lower confidence limit indicating to not it's ascertainment in the reality of the human capital .

This differs from the findings of ( Saleh I. E , 2011) (6) study that indicates the importance of the human capital availability among the requirements of the intellectual capital inside work organizations where this helps in achieving good administrative work development of the organizations in which the intellectual capital is available where it contributes in achieving the organization message and vision .

The percent of the axis mean response as a whole ( 0.05) was less than lower confidence limit indicating to not it's achievement in the reality of the human capital in Egyptian weight lifting federation and this requires larger increase and interest from the study about increasing the qualified human capacities wealth with investing the human potentials in authorship and generating knowledge, consequently increasing the knowledge wealth of the federation that is reflected in achieving the competitive advantage with civil and world sport federations and to be in line with Egypt vision 2030 in achieving good sport progress based upon the trained and qualified human energies .

( Mohammed A. , 2003)(17) indicates the importance of the human element availability capable of achieving the work that helps in promoting and advancing the organization in which the trained human element is available and who possesses the sufficient skills and information of the work nature inside the organization.

It is shown from table ( 7 ) that mean responses of the sample individuals about the statements of the second axis " managing the structural capital " ranged between (0.44:0.79) and the mean response of the axis as a whole was ( 0.54$)$.

Where the responses of the study sample individuals were on behalf of the more frequent response that is "no ", except the statement (8) on behalf of the response " yes " and the statement (12 ) on behalf the response " somewhat ".

The researcher explains this finding pertaining with the statement (8) with the mean response higher than upper confidence limit, since it is considered one of the most practices that are available for developing the structural capital in the federation that there are clear regulations and laws determining the posts and works nature inside it, this is considered a clear signal that the process of developing the intellectual capital related with change in the structural capital is related with the extent of the rules availability organizing the institutional work . Based upon this, the development, change, generating knowledge, information and concepts in the frame of clear systems and laws governing the work nature inside the federation and it's branches .

These findings accord with the finding of ( Ali T, , Salima T. , 2011)(12) study indicating that among the dimensions of the structural capital is the existence of clear law regulations and legislations to determine the work nature in which different tasks and functions are determined in the organization that are considered one of the basic components for systems and regulations inside these management organizations

While the responses of the sample individuals towards the statement ( 6 ) registered lower confidence limit and includes this statement stating that " the rules and bases that govern the work in Egyptian weight lifting federation are documented in regulations and booklets pronounced for all " indicating it's ascertainment and 
practice inside the federation moderately. The researcher attributes this to the nature of the administrative work, where the internal rules and regulations of the federation and the external regulations of different authorities in works nature are applied. This is considered among the basic components to achieve the organizational culture inside the federation, but it is ascertained moderately because of the instability these regulations and laws and modify them continuously .

Adel Harhoush , 2007 )(9) indicates the necessity of providing the internal rules of the institutional work and the flexibility of these rules and not contradict with the general rules of the work nature. The institutions must maintain different administrative rules with modifying and clarifying them for the employees, so that the knowledge is generated that includes the interpretations of these different rules .

The response of the sample individuals towards the statement (8) stating that " Egyptian weight lifting federation provides opportunities of foreign participations for cooperation in achieving the clear vision for the society with providing the full support for the foreign society "with a mean response of ( 0.57 ) and it is less than lower confidence limit indicating it's ascertainment less than the mean inside the structural capital .

The researcher attributes this to non-spreading the game on the required level inside Arab Republic of Egypt and following establishing national centers in territories governorates in spite of achieving the best records on the local and international level, consequently, the level of societal communication with federation is considered little. So , the federation must communicate through operating the role of regions ( branches ) subjected to federation in different governorates, since the process of the societal communication and changing the methodology followed in work is considered among the mechanisms of developing the structural capital that is considered among the dimensions of intellectual capital for the federation .

The researcher agrees with the findings of ( Reda S. , 2009 )(3) study showing the role of the intellectual capital in achieving the competitive advantage of the organizations, where the structural capital contributes among the mechanisms of developing the human performance inside the organizations, that in turn contribute in achieving knowledge and information in work that is reflected in turn of the employees performance on the level of functional performance .

Whereas the responses of the sample individuals about the statements $(1,2$, $3,5,7,9,10,11,12$ ) were less than lower confidence limit indicating to not it's ascertainment in the reality of the structural capital .

The researcher attributes this to these practices gain of a low level of the response due to unavailability of modern administrative, technical information, that the federation doesn't possess modern systems in management information systems and depending on the traditional methods in work that influence the level of flowing knowledge and generating information .

This finding differs from the findings of ( Maher M. , 2016 ) (15) study indicating the presence and availability of good intellectual capital inside universities contributes in achieving creativity and effectiveness in the functional performance inside Syrian universities . 
Whereas the axis as a whole achieved mean response of ( 0.54$)$ and it is a percent less than the minimum, where the response of the sample individuals less than the mean in achieving the dimension of the structural capital and this is considered less than the required in achieving the intellectual capital inside Egyptian weight lifting federation .

The findings of ( Catherine , Patrick , Harrington, 2009 ) (24)study indicate that the availability of the intellectual capital with it's different dimensions in achieving the competitive privilege for the tourism organizations .

The researcher indicates that Egyptian weight lifting federation must develop the organizational structure and must be flexible enough to guarantee performing the tasks and works easily and distinctively with developing general policies for it to guarantee achieving the competitive privileges with other sport organizations .

The researcher sees that it must put specific goals for Egyptian weight lifting federation and compare the real performance with the expected findings and that Egyptian weight lifting federation is keen to develop and update information, data systems and the administrative processes continuously in a way achieving excellence in performance.

The findings of both ( Myson ., 2016 ) (21) , ( Maher M., 2009 )(14) study indicate to the necessity of operating the role of institutions in determining specializations and responsibilities with providing a comprehensive guide to work inside it , the researcher sees that developing the organizational structure for Egyptian weight lifting federation represents an important condition to form the organizational culture supporting the successful management thinking development and this accords with the findings of both ( Mention ,A.,2012 )(26), ( Mitchell .h, 2009 )(27) study that confirms the importance of developing the management thinking prevalent in different administrative organizations.

It is shown from table (8) that the mean responses of the sample individuals of the third axis statements " managing relations capital " ranged between ( $0.39: 0.72)$.

Where the responses of the study sample individuals were on behalf of more frequent response that is " No " except the statement ( 5, 9 ) was on behalf of the response " somewhat".

The researcher attributes this finding of the statement $(5,9)$ to the importance of the investors presence and the contribution in operating the role of federation activities to increase the financial support because of the littleness of the support offered by the government authorities . These findings accord with the findings of (Yahia M. , 2010)(23) study indicating the necessity of developing a clear strategy in sport institutions to polarize the investors and business men to contribute in succeeding different activities inside them and help to achieve their annual plans and activities .

Whereas the percent's of the statements $(2,4,8)$ ranged between lower upper confidence limit indicating to its ascertainment moderately in the reality of managing relations capital in Egyptian weight lifting federation .

The researcher attributes this finding related with the statements to the practices nature that Egyptian weight lifting federation follows in functional relations and tasks from solving problems, constructing information and others, but this work 
isn't performed in the required form and there is slowness in executing the functional and administrative decisions pertaining this work. The researcher attributes this to the littleness of good experiences, knowledge and information in full communication skills with the beneficiaries from the activities of Egyptian weight lifting federation .

These findings differs from the findings of ( Ahmed I., 2014 ) ( 1 ) study indicating the importance of the functional and administrative experiences and information availability inside Egyptian sport clubs, where this helps to take the successful management decisions that contribute in achieving the competitive privilege .

Taha Hussein (2010 ) (8) indicates that it is necessary for the successful administrative organizations that seek to achieve the competitive privilege to be able to achieve balance between the work nature and the external needs for the clients so that they can achieve the successful competitive privilege .

The responses of the statements $(6,7)$ were less than the lower limit slightly, where it indicates to its ascertainment with a percent less than the mean inside Egyptian weight lifting federation .

The researcher interprets this percent that Egyptian weight lifting federation has not been surveyed the clients opinions of the activities and services that are offered, consequently, there are no sufficient information of external society needs that it deals with, so this is considered among the obstacles of relations capital inside Egyptian weight lifting federation .

( Hany M., 2008 )(22) indicates the necessity of management organizations adopting the different aspects to achieve modern and contemporary management start that contributes in achieving good vision for works that is reflected positively in providing good knowledge for data and figures inside these organizations during work

The statements $(1,3,10,11,12)$ came with means response less than lower confidence limit indicating to not it's ascertainment in relations capital at Egyptian weight lifting federation .

The researcher attributes these weak practices inside Egyptian weight lifting federation because the top management in federation doesn't study the needs of foreign market, providing sufficient figures, statistics and data of the work, as well as there is no a competence specialized in marketing and public relations causing the difficulty of communicating appropriately with the beneficiaries from the federation activities from trainers, referees, athletes, administrators and others .

The findings of ( Mayson A. , 2016 )(21) study indicate that through the successful institutional work inside different management organizations according to its work nature, they must have the sufficient knowledge in the necessary data, statistics and findings for decision maker to achieve the comprehensive vision in constructing the successful management decision .

The sum of the axis as a whole obtained a response of ( 0.58$)$ and it is less than the lower confidence limit indicating the ascertainment of relations capital axis inside Egyptian weight lifting federation with a percent less than the mean .

The researcher interprets this percent because of the vision visibility in Egyptian federation and there is no site on international information network ( the internet ) that includes all different and varied data and information of weight lifting 
sport, different federation activities and all the necessary data and information so that all can benefit from it . All these help in constructing a broad vision of the federation nature and how to communicate with it and what is the role the federation plays in spreading and establishing the game on local and international levels .

The researcher attributes this finding that the intellectual capital relates completely and closely with the institutional performance . Intellectual capital and its basic components is considered one of the main criteria in which it's availability guarantees achieving goals and interests of the employees and federation management as a whole that reflect in turn the leaderships responsible for the federation management .

These findings accord with (Saleh A. , 2011) (6) study indicating the necessity of providing the sufficient information of the organization and its employees as much as it can know the training and specialization needs that are necessary to develop the human component strongly to keep pace with modern scientific developments .

\section{Conclusions:}

1- Lowering the reality of the intellectual capital in Egyptian weight lifting federation and there are no mechanisms to develop the level of the employees performance .

2- Reducing the level of the competitive privilege at Egyptian weight lifting federation .

3- There is no sufficient awareness with the dimensions of the intellectual capital management (human - structure - relations ) inside Egyptian weight lifting federation

4- The littleness of knowledge requirements availability, generating and industrializing it inside Egyptian weight lifting federation .

5 - There are conflicts between employees in the federation on the management posts .

6- The difficulty of different data and information in the federation because there is no an operated electronic site for Egyptian weight lifting federation .

7- Decreasing the level of the institutional performance as a whole with it's different items inside Egyptian weight lifting federation.

8- The researcher reached to construct the proposed concept of intellectual capital management in the Egyptian Weight Lifting Federation in the light of the knowledge economy, as follows:

\section{Recommendations:}

1- The necessity of applying the suggested conception to develop the intellectual capital in Egyptian weight lifting federation that can be followed in educating, qualifying and preparing the employees to guarantee good preparation for the competent administrative leaders and leaderships in the field of achieving the competitive privilege in the federation .

2- The necessity of adopting the culture of managing and investing the intellectual capital through maintaining and developing it continuously as an infinite strategic resource .

3- The nation must work on encouraging business men and investors to invest in sport federations and giving the necessary facilitates , preparing a climate to invest and 
capture internal and foreign capitals for investment in sport installations .

4- The necessity of dealing with the intellectual capital as a basic and strategic resource between the resources that sport federations possess, maintaining and developing it continuously .

5- Making communication channels open and available for employees to obtain information and data by using information technology to be known for all employees to be participants in decision making not executive only .

\section{The suggested future studies:}

Despite the findings of applied implications for the study and the related recommendations, the study revealed also another number of the study points that have important contents that serve as future suggested researches to support applying the suggested conception, these points are :

1- A study case and comparing with other international foreign federations and determining the requirements of the digital economy between these federations and the extent of it's success in sport field .

2- The role of information systems in predicting the work problems in the branches subjected for Egyptian weight lifting federation. 


\section{References :}

Abdel Rahman ., Faaza M.A.(2007) . Method and economy, Oman , Dar Almassira for publication and distribution .

Adel H. (2007) .The intellectual capital , methods of measuring and maintaing it ", Arabic organization for management development, Cairo, the first1edition .

Ahme. E. ( 2014 ) . The competitive advantage for developing Egyptian sport clubs, (unpublished master thesis), faculty of physical education for boys , Helwan university .

Ahmed El Bana. (2016 ). The role of the intellectual capital in developing the competitive abilities for Assuit university students ( a field study), Educational journal, faculty of education -Sohag, Sohag university .

Ahmed S. M. ( 2004 ). Managing the human resources : modern management for the intellectual capital ", Cairo .

Ali Elselmi (2008). Managing the human resources "an strategic perspective, Dar Alghareeb for printing and publication, Cairo .

Ali T. , Solima T. (2011) . The role of strategic facility for the intellectual capital in supporting continuous competition for the institution under knowledge economy - a case study of the Algeria company for insurance, The Fifthth International Meting, faculty of economical and commercial sciences for facility sciences, Hssiba Ben Bouali -Chelf university, Algeria , 13-14 December .

Catherine, Patrick, Harrington.(2009). Managing intellectual capital for a sustaining competitive advantage in the lrish tourism industry in: the tourism and hospitality research in Ireland conference.

Hany M. (2008) .The effect of the intellectual capital , a contemporary management start, Dar Elsahaab for publication and distribution, Cairo.

Kęstutis K., Rasa .(2006).The Assessment Models of Knowledge-Based Economy Penetration ,ENGINEERING ECONOMICS, No 5 p (40).

Louiza F. (2016) . The role of the intellectual capital in achieving the competitive privilege for the economic institutions under knowledge economy, a case study of cement company Ain Touta ,A Doctoral thesis , faculty of economical and commercial science and facility science, Mohamed Khider university - Biskera, Algeria .

Magdy M. ( 2004 ). Functioning electronic marketing as a tool for excellence in work organizations, work paper in the second 2 management meeting holding by Saudi society for management entitled " Management and global new changes ", Riyadh / Saudi Arabia , 7-8 March .

Maher H. (2009) . The role of knowledge economy in enforcing the competitive abilities for Arabic woman, work paper presented to the national workshop , developing occupational skills and competitive abilities for Arabic woman, Arabic work Organization, Damascus, Arab Republic of Syria .

Maher M.M. (2016) . The effect of the intellectual capital on the creative performance in Syrian universities ( a field study - Tishreen university ), A master thesis, faculty of economy, Tishreen university .

Mahmoud.,Mahmoud M. A. (2010) .The effect of the intellectual capital on innovation in Jordan banks ( a field study ), journal of Damascus university for economical and law science, Volu.26, No.2

Mayson. A. (2016) .The intellectual capital and it's relation with institutional performance quality ", an applied study on education program at URWA 
agency / Gaza, A master thesis , Academy of management and policy for post graduates studies, Alaqsa university, Gaza .

Mention, A.,(2012). Intellectual Capital, Innovation and Performance: A Systematic Review of the Literature", Business and Economic Research. Vol., 2, No., 1.

Mitchell.h,(2010).Study, a model for managing intellectual capital to generate wealth , (a thesis of doctor of philosophy in business), new Zealand, Massey university.

Mohadese F \&Mohammad H.(2016).The Relationship between Intellectual Capital and Organizational Innovation among Faculty Members of International University of Yazd, Iran, International Journal of Humanities and Cultural Studies Issn 2356-5926.

Mohammed Al. (2003).Managing individuals and human relations, firstledition, Dar Qandeel for publication and distribution, Oman.

Mohammed S.G.(2009) . Developing education and it's role in knowledge economy, First1 International conference of electronic education - learning industry for the future, Riyadh.

Mourad. E. (2011) .Arabic nations preparation for integration in knowledge economy - an analytical theoretical study ,the Eighth world conference of Islamic economy and funding, Doha, Qatar.

Reda I, Saleh .( 2009) . The intellectual capital and it's role in achieving the competitive advantage for the organizations, International conference of management development entitled " towards an excellent performance in the government sector " , Institute of general management, Riyadh, Saudi Arabia , from 1- 4 February .

Saleh I. A.( 2011). The effect of the intellectual capital on technological perfection and it!s reflections on lowering the cost by applying on the national company for domestic furniture industries , Naynawa ", journal of Anbar university for economical and management sciences, the fourth volume, No.7.

Sayed ElBawab. (2001) . Contemporary technological scientific revolution ( the third industrial revolution ) it!s entity, axes , findings and effect, the second edition , Albayan for printing and publication, Cairo

Seliem, A., Ashour, A., \&Bontis, N., (2007)."Human Capital and Organizational Performance: A Study of Egyptian Soft Ware Companies, Management Decision, Vol., 45, No., 4.

Sheikhali, Z. M., Fariba(2014). The model of relationships between intellectual capital and knowledge management with organizational innovation among the faculty members of Isfahan University of Medical Sciences. International Journal of Scientific.

Taha H. ( 2010 ). Investment in knowledge capital and it's role in constructing the competitive privilege for the organization, the scientific journal , no.2, faculty of commerce, Helwan university .

Taleha H , Adela., E. (1997) . An introduction in sport management , Book house for publication, Cairo .

Yahia B.M. (2010) . A suggested strategy for capture capitals for investing in Kuwait clubs ,( a published master thesis), faculty of physical education , Banha university . 